\title{
NA FLUIDEZ DO CORAÇÃO PARA UMA ANTROPOLOGIA DO AMOR E DA RELIGIÃO
}

\author{
Sèna Annick Laetitia Abiou ${ }^{1}$
}

\section{Introdução}

As reflexões e análises que contribuíram para escolha e determinação desse campo de estudo nasceram em Benin, África, no decorrer de meu contato com o meio religioso católico, cujas estruturas e normas são bem determinadas. No âmbito público, as ações e interações entre igrejas católicas e templos de voduns, a meu ver, pareciam caracterizar-se por uma violência verbal orientada pelos preconceitos. Tensão que torna difícil a convivência entre membros de ambas as religiões. Mas ao nível mais privado, a realidade cotidiana era outra.

A fé cristã na sociedade Beninense às vezes é marcada pelo sincretismo religioso que estabelece uma ponte entre a religião do colonizador, católica, e as tradições autóctones. A análise das maneiras de viver, ser e fazer dos fiéis parece, portanto, revelar que a religião vai muito além das fronteiras institucionais e simbólicas que comumente fixamos.

O Brasil, nesse contexto, apresenta uma riqueza e diversidade religiosa favorável para análise de tal fato. Desde Nina Rodrigues, Cândido Procópio, Roger Bastide até hoje, nota-se uma produção bibliográfica abundante no campo denominado afrobrasileiro. As preocupações dos autores são múltiplas e em geral focadas na procura das origens, estudo de sincretismo a partir da perspectiva de explicação dos traços de origens. Nos quadros desse artigo, no entanto, meu objeto de estudo se insere no mesmo dinamismo das pesquisas feitas por Yvonne Maggie no livro: Guerras de Orixá, Um estudo de ritual e conflito (2001). Sem pretender estudar as religiões afro-brasileiras em si, minha preocupação é fazer um estudo etnográfico no "Ilê do paizinho" de Viamão, Rio Grande do Sul, uma casa de religião de meio urbana de culto batuque e da nação Oyó. Nesse universo específico, meu objetivo principal foi pesquisar o cotidiano profano e religioso, público e privado.

Tendo em vista que o ideal de filhos de santo se formula nas palavras: "um por todos e todos por um", pretendi analisar a sociabilidade expressa nas relações interpessoais entre indivíduos de um lado e indivíduo e coletividade de outro. A

${ }^{1}$ Universidade Federal do Rio Grande do Sul, Brasil.

Iluminuras, Porto Alegre, v.12, n. 28, p. 209-221, jul./dez. 2011 
determinação da lógica dessa sociabilidade me permitiu fazer uma tentativa de explicação da fluidez do coração, entendido como o simbolismo de um corpo pensante observável na experiência empírica através de expressões totais das pessoas: corpo/mente, gestos, relações entre indivíduos e sociedade; considerando a casa de religião como uma sociedade mais restrita inscrita em outra mais ampla. Tudo isso para descobrir a configuração do "amor", o que ele é para o grupo, como eles pretendem vivê-lo e como eles o vivem.

Para chegar a esses objetivos, pretendo questionar o "como" se forma e o "como" se manifesta esse corpo pensante através de análises de algumas categorias subjetivas e objetivas na vida dos membros da casa. Os processos de socialização e de sociabilidade. Na socialização podemos determinar as particularidades entre indivíduos mediante análise do tipo de formação, suas historias e trajetórias de vidas. Como se formou o "eu". No processo de sociabilidade, como se forma na pontualidade o "eu" a partir do "eu" de outro e de "nós", isto é, como esse "eu" interage com os outros nos diversos quadros do real.

A minha preocupação inicial foi analisar separadamente os três eixos temáticos de individualidade, sociabilidade e memória, mas eles se apresentam no campo estudado como processos dentro do processo, portanto, optei por fazer uma análise de conjunto. Assim, na primeira parte descrevi a casa de religião, a minha inserção nesse universo, apresentando algumas narrativas recolhidas das entrevistas com o líder do grupo. Na segunda parte, fiz uma análise das construções de individualidade, sociabilidade e memória. Analisei alguns aspetos do amor, partindo apenas dos modelos observados no grupo. Como dificuldades inerentes à realização do estudo, foi um dilema trabalhar os aspectos públicos e privados dos membros, o que era parte do universo comum e ao mesmo tempo confidencial para os informantes.

Uma vez que não há vida privada que não seja social, resolvi trabalhar nesse artigo alguns fatos ocorridos na vida dos informantes, na medida em que isso está estreitamente relacionado com a sociabilidade no grupo. A meu ver esses fatos fazem parte do meu objeto de pesquisa. O registro "privado" interfere direta e cotidianamente na vida da casa. Não são segredos, mas fatos que preciso manipular com discrição, fazendo economia de detalhes por respeito aos informantes. 


\section{Etnografando a casa da religião}

O meu primeiro contato com o grupo foi através do pai de santo, que me apresentou ao coletivo com grande entusiasmo como "uma africana", quase uma representante do axé da "Mãe África". A Casa foi fundada em 8/12/1988 e conta 18 membros no período da pesquisa. Ela é classificada pelos membros como uma casa e não um terreiro, pois para o Babalorixá, isto é, o pai de santo do grupo, uma casa supera em importância um terreiro no sentido da fiabilidade aos fundamentos de religião. "Nós somos uma casa e não qualquer terreiro" (Nilsom da Cunha, 22/08/2010). Disse ele, me convidando a mudar minhas categorias de classificação.

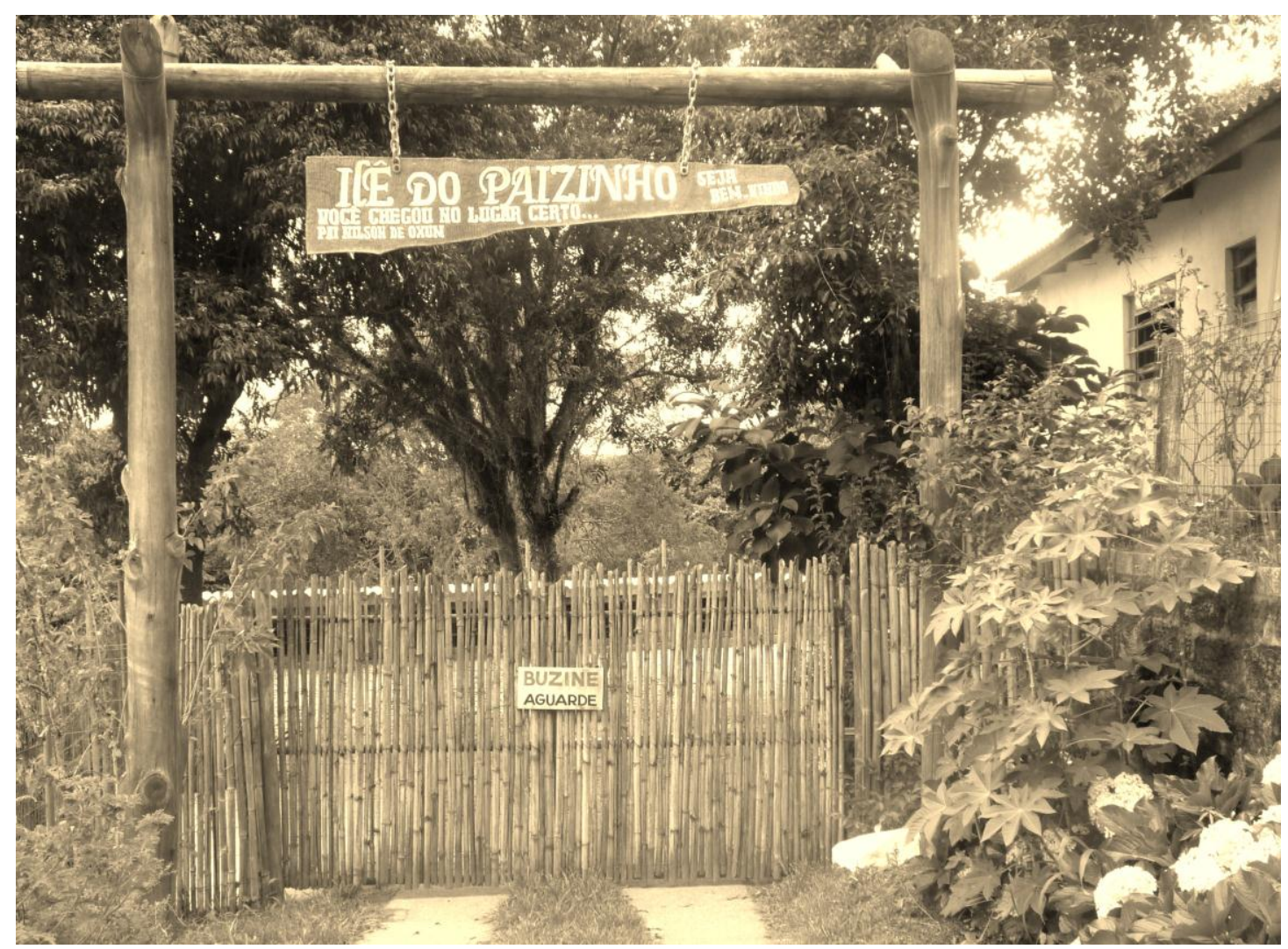

Entrada do Ilê do Paizinho. Foto de 21/12/2010 - autoria de Sèna A. L. Abiou ${ }^{2}$

A socialização no Ilê pretende ficar muito fiel na transmissão da tradição:

"Religião de matriz africana é uma cultura linda. A Bíblia é uma regra escrita e as pessoas se referem aos capítulos. Religião de matriz africana não tem Bíblia e a responsabilidade de ensinamento é sagrada. O que o pai de santo ensina na oralidade é a verdade. É observamos diretamente a aprendizagem do filho, por isso exigimos sua dedicação. A prova para passar o axé neles é a dedicação".

(Nilsom da Cunha 30/08/2010).

${ }^{2}$ Todas as imagens usadas na pesquisa foram consentidas.

Iluminuras, Porto Alegre, v.12, n. 28, p. 209-221, jul./dez. 2011 
A socialização no grupo passa então por um processo de dedicação aos assuntos religiosos. De origens diferentes, pertencendo a diferentes camadas da sociedade, os membros do Ilê recebem no decorrer da formação uma educação de santo que consagra a socialização deles no âmbito religioso particular. A demarcação do espaço "nação" específico faz parte dos elementos de classificação da casa numa espécie de família simbólica, cujas relações de parentesco e de afetividade emergem nos processos da formação, novamente socialização e transmissão de uma memória do grupo cada vez atualizada. Nilsom, o Babalorixá, aceita filhos e filhas para uma "gestação simbólica" através da formação que abranja todos os aspetos da vida.

A Casa, o Ilê é assim uma escola humana e se encontra no meio de uma vegetação exuberante que combina árvores gigantescas, pássaros, animais e uma cachoeira no centro representando um santuário, quer dizer, a presença da mãe Oxum. $\mathrm{O}$ Ilê não se limite às fronteiras materiais da casa, ele abrange também espaços públicos da sociedade mais ampla como o mercado público, a praia, a Igreja Nossa Senhora do Rosário, a encruzilhada.

Diversos rituais de obrigações estruturam os encontros dos membros que se tornam momentos de grande sociabilidade. Além desses encontros, há assembléias às terças-feiras durante os quais o grupo trata de diversos aspetos práticos da casa. O líder foi meu informante principal e praticamente "exclusivo" durante a pesquisa. Ele centraliza o poder espiritual, material e político do grupo, decide a organização de atividades, divisões de tarefas de tal forma que todas as entrevistas com outros membros se mostraram difíceis inicialmente, isto é, restritas. "Pergunta para ele", "é ele quem sabe", "ele vai saber te dizer melhor", são frases que começam ou terminam meus diálogos com eles.

\section{O Babalorixá :}

Nilsom nasceu em 22/08/1950, natural do Rio Grande do Sul. Sua mãe é católica, Silva da Cunha, falecida em 1956. Seu pai, Niger Cordova da Cunha, tornou-se devoto da religião de matriz africana nos sete últimos anos de sua vida. Seus avós maternos são católicos e os paternos são de religião espírita. O contato de Nilsom com o batuque, segundo seu relato, começou já na infância quando ele acompanhava a tia paterna Manoela à casa de religião Batuque de Dona Maria filha de Ogum. "Foi assim 
que nasceu mеи desejo de participar de uma casa de religião afro. Sentia muitas vibrações, necessidade de participar”.

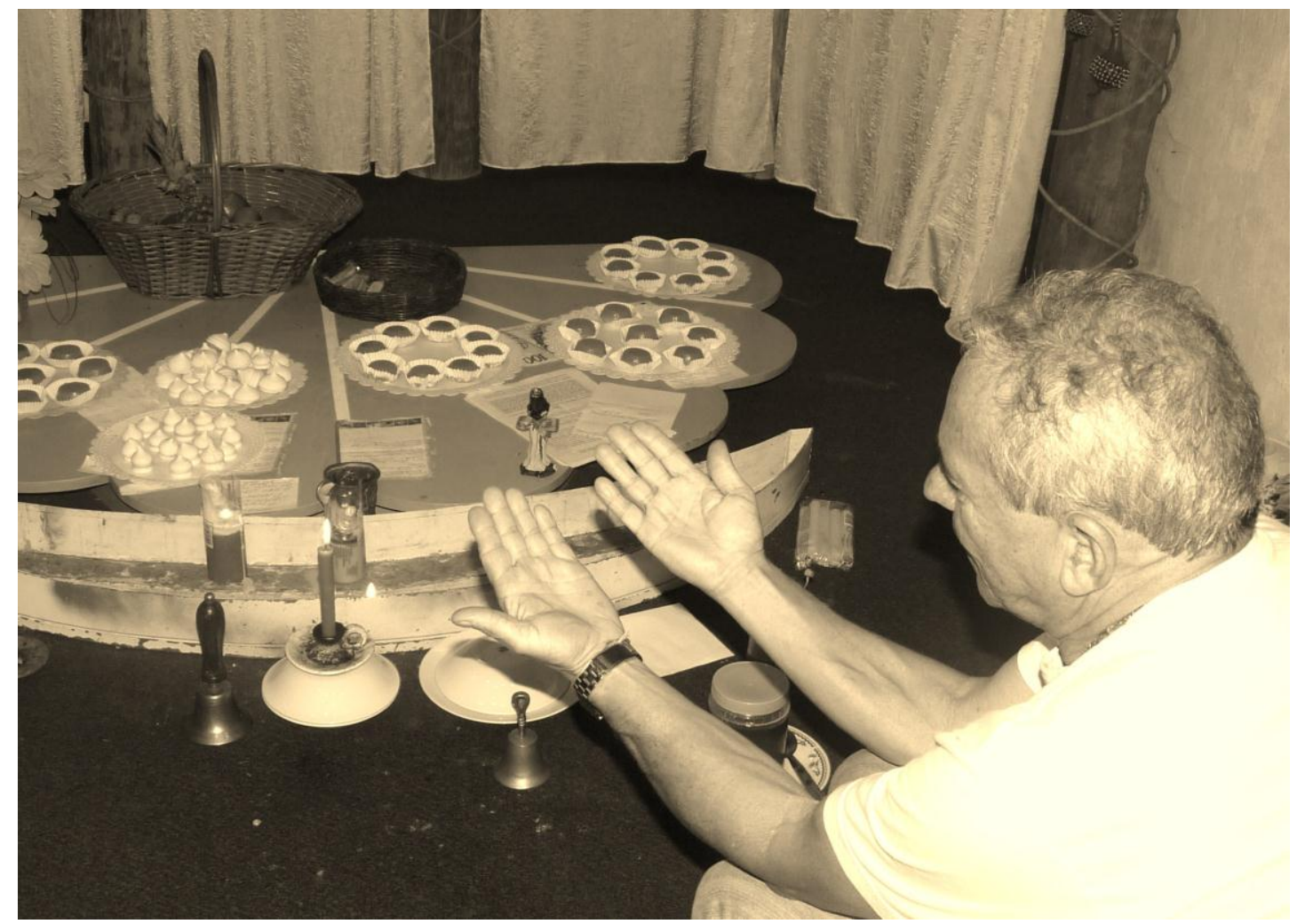

Pai Nilsom no quarto de santo. Foto de 16/04/2011 - autoria de Sèna A. L. Abiou ${ }^{3}$

Nilsom contou-me também que na adolescência teve uma vocação sacerdotal não sucedida, originada de uma admiração por seu tio Libero Ventorini Cordova, que era sacerdote da Igreja Anglicana. Nilsom foi se matricular no seminário para se tornar sacerdote também. Mas devido à resistência familiar, do irmão mais velho Sergio Ladario da Cunha e do tio Thaso Cordova da Cunha, ele desistiu.

"Enquanto eu for vivo, ele vai para lugar nenhum. O Pinguim vai ficar comigo". São palavras do tio que no mesmo tempo não se importava de o ver frequentar o terreiro. Aos 20 anos namorou e foi noivo de sua prima, Racheal Parenz da Silva. Em seguida encontrou Maria da Graça Bombella com quem teve quatro filhos.

No inicio da minha inserção no campo, o pai Nilsom estava junto com a companheira, Maria da Graça Bombella, mas no decorrer da pesquisa ficou novamente solteiro. Com Maria da Graça, pai Nilsom passou 35 anos de sua vida até a crise que

${ }^{3}$ Todas as imagens usadas na pesquisa foram consentidas.

Iluminuras, Porto Alegre, v.12, n. 28, p. 209-221, jul./dez. 2011 
separou o casal. Maria da Graça Bombella abandonou o lar conjugal a partir de uma situação que ela qualificou como falta de respeito à sua pessoa em presença dos filhos de santo. Durante o tempo que ficou sozinho, Nilsom namorou uma das clientes da casa. Maria, no entanto, voltou para casa, mas para Nilsom não tinha mais possibilidade de reconciliação. Segundo ele, os Orixás estão também de acordo com essa decisão.

A situação de separação do casal fragilizou até certo ponto a casa da religião. A situação não melhorou com ameaças de venda da casa de religião, pelo contrário, desencadeou outra breve crise entre o casal chave: Felipe e Patrícia, a mãe pequena. Nilsom afirma que quando falecer será talvez o fim da casa, por falta de um sucessor.

\section{Análise de individualidade, sociabilidade e memória da casa do amor}

A sociabilidade vivenciada na casa passa por um filtro de informação. Ela engloba só aquilo que transparece nas características comportamentais de uns e outros membros. Implica coisas banais como habilidades, capacidades de saberes e fazeres culinários, expressão oral e facial, agradabilidade nas conversas etc.

Os membros do grupo se sentem inseridos num tempo-espaço familiar que vai além do real e abrange o místico. O referencial do espaço vivido por eles se apresenta como produto das relações entre homens e Orixás possibilitando novas formas de pertencimento que vão além dos limites materiais, dos lugares e espaços reconhecidos da casa de santo, para se tornar mais abrangente, incluindo um espaço místico e consagrando um fluxo constante entre o visível e o invisível, o humano e o divino. Isso nos faz pensar por analogia à sociabilidade das redes eletrônicas no comentário de Silva.

\footnotetext{
Na rede, o indivíduo pode pertencer a um lugar que não existe, já que se apresenta como simulacro. Embora possa ser esvaziado de afetividade e sem história, esse "lugar" dá sentido a um tipo de relação social através de uma localização virtual cujo acesso é via chave eletrônica, ou seja, de um endereço (www, @, FTP, ICQ etc) que identifique o domínio de onde o usuário está inserido. É no anonimato do "lugar virtual" que se experimenta solitariamente uma nova sociabilidade (Silva, 2007).
}

O virtual aqui passa a ser o místico e esse "lugar imaterial" dá sentido a um tipo de relação social cujo acesso é via a iniciação de santo, a crença no santo. Isto para incluir também nessa forma de sociabilidade a clientela da casa de religião.

O jogo de búzios ou as previsões do pai de santo determinam os Orixás de cabeças dos filhos e filhas de santos e, consequentemente, temperamentos e atitudes que 
se encontram predeterminados como desses orixás. Ser filho de Oxum, de Ogum ou de Xangô, não quer dizer outra coisa se não a identificação dos parâmetros a partir dos quais o membro está classificado. Não tem anonimato do lugar "místico", mas a partir das particularidades de cada pessoa, particularidades determinadas por identificação aos Orixás, eles experimentam individual e coletivamente uma nova sociabilidade que podemos chamar nesse campo religioso de a sociabilidade de santo.

As tarefas desempenhadas nos rituais testemunham uma individualidade que orienta também a sociabilidade de fato, pois as tarefas são complemento obrigatório da necessidade de se relacionar na estrutura do ritual.

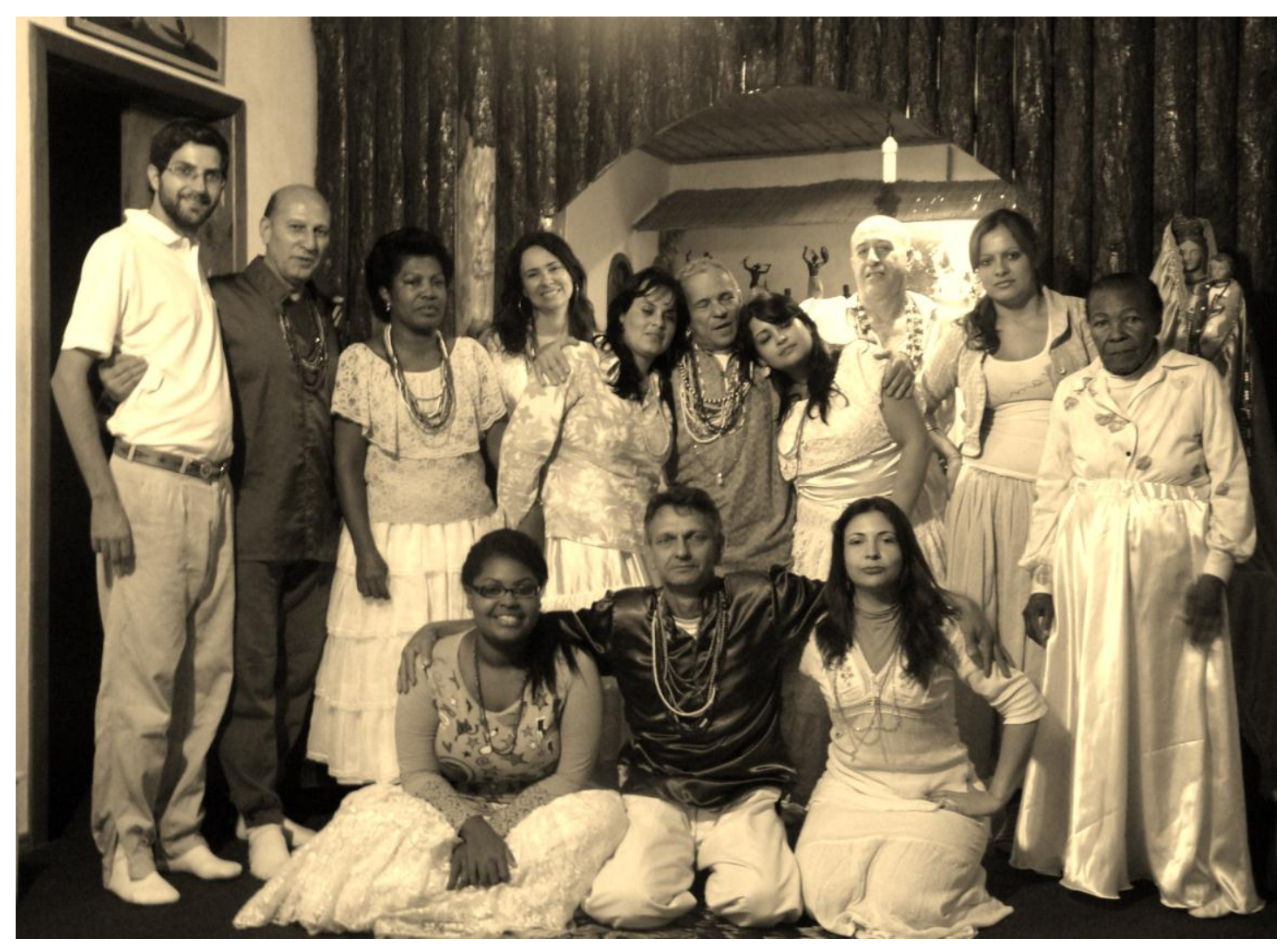

Foto de familia de alguns dos membros da Ilê. Foto de 23/04/2011 - autoria de Sèna A. L. Abiou ${ }^{4}$

A moral fundamental do grupo estipula um ideal de vida perceptível nas palavras "todos por um e um por todos". Verificando a mitologia dos Orixás, não verifica-se claramente a sociabilidade e convivialidade entre os mesmos. Por consequiência, esse desejo de unidade, comunhão e fraternidade unânime entre o grupo obedece à necessidade de ser um, de viver em sintonia.

${ }^{4}$ Todas as imagens usadas na pesquisa foram consentidas.

Iluminuras, Porto Alegre, v.12, n. 28, p. 209-221, jul./dez. 2011 
A análise dos processos de inserção dos membros da casa da religião revela uma luta contra a solidão. Diversas situações de vida tinham possibilitado esse encontro de homens e mulheres à procura de felicidade. Aspirações de fraternidade mais estrita, procura de companheira de vida são, nos casos estudados, as razões fundamentais pelas quais esses indivíduos tinham decidido compartilhar uma cosmologia que pudesse ajudá-los a alcançar esses objetivos.

Com objetivo de compreender melhor essa forma de sociabilidade vivenciada na casa de religião, procurei saber o que na mitologia dos Orixás poderia pressupor essa vida de unidade. Em certo nível nas histórias mitológicas, há afinidade entre tal Orixá e outro, mas não existe uma tendência geral. Os Orixás vivem tanto de amor como de guerras. Assim, procurei também entender nos rituais e na vida quotidiana da casa como essa unidade se apresenta. De fato, dá para sublinhar certa complementaridade nos papéis desempenhados pelos Orixás. Esses papéis traduzidos nas tarefas dos filhos de santo da casa durante cerimônias e obrigações já mencionadas anteriormente, favorecem o sentimento de equipe. Eles se organizam em um corpo único composto de diversos membros. Fatos observados em todas as assembléias ordinárias e de maneira relevante durante a cerimônia de limpeza de corpo de fim de ano. Esse é o momento fatídico para abrir os caminhos do ano seguinte e todos se mostram solidários no trabalho.

Uma das interpretações possíveis desse programa de vida solidária é devido às influências que o Batuque estabelece com outras religiões. Mas sem entrar nessa hipótese nos quadros desse artigo, optei por analisar a forma de sociabilidade a partir das necessidades práticas do próprio fato de “estar junto". São essas necessidades práticas da ação que modelam as relações interpessoais. Preocupações de equidade e de justiça para todos conduzem eles a construir a partir de valores morais, as aspirações de equidade já presente na sociedade mais ampla. Aqui, elas se apresentam em formas solidárias de fraternidade espontânea. Os contatos na formação dos filhos de santo significam trocas de proximidade; as construções discursivas orientadas a esse fim para reforçar o sentimento de unidade testemunham este fato.

O sujeito opera um deslocamento tanto ao nível individual quanto ao coletivo. Ele se coloca no lugar do "outro" e do "nós" para ver ele como um simulacro. No ato de viver para "todos", o sujeito para se relacionar interpreta empiricamente as experiências cotidianas aos três níveis de si, para si e para o outro. Assim, ele precisa sentir em si as necessidades afetivas e práticas do outro para responder a elas como se fossem pessoais, 
isso implica estar atento, saber ouvir e sentir. Os abraços, "toques amistosos" espontâneos ou superficiais parecem fatos de menor importância, mas tudo é uma comunicação que estrutura a forma de sociabilizar-se que os membros da casa experimentam. Essa sociabilidade descrita é concreta. Eu a observei nas relações entre eles, mas ela é ainda "anônima" e apresenta as aparências de uma homogeneidade de comportamento que eu procurei analisar para uma leitura mais explicita de lógicas internas de funcionamento. Os indivíduos não se relacionam um com os outros do mesmo modo e as afinidades entre casais naturais se traduzem em afinidade de santo. De fora para dentro, os casais membros da casa se tornam a princípio irmãos na religião e são chamados a viver uma fraternidade além de toda contingência e constrangimento, mas o fato é que essas afinidades se preservam na religião seccionando o grupo em núcleo de sociabilidade por "grau de intimidade". Isso se observa ainda de forma mais aguçada nos momentos de crises entre casais. No primeiro exemplo, a crise entre o pai de Santo pai Nilsom e sua mulher teve uma repercussão muito forte na vida da Casa. As fronteiras, que ele tentava colocar entre a sua vida privada e sua vida religiosa, foram rompidas. Notei uma breve desorientação afetiva nele, nas dificuldades de organizar-se sozinho, tanto em relação aos assuntos da vida cotidiana como da religião.

Quanto a Felipe e Patrícia, a mãe pequena, a crise entre o casal originou a insatisfação de Patrícia com a religião e a desconfiança momentânea do pai de Santo na relação com Felipe. "Não se pode esconder fatos para seu pai de santo" (Nilsom da Cunha 30/08/2010). Outros fatos relevantes nas estruturas de sociabilidade no grupo encontram-se nas narrativas do líder avaliando os filhos em seus processos de formação. Aqui, as capacidades intelectuais e posições sociais ocupadas pelos membros que tem grandes responsabilidades na sociedade mais ampla encontram também na religião a admiração e a confiança do líder. Na construção da sociabilidade se observa também a construção da individualidade, pois nas interações, as particularidades e irredutibilidade entre indivíduos transparecem. Isso de fato, como "a outra cara da moeda", favorece rivalidades e situações de conflito de interesse.

A Casa da religião que no início pretendeu ser um campo neutro de encontro das diversidades tornou-se certa reprodução da sociedade mais ampla nas suas desigualdades e problemas que criam conflitos. Assim, na própria necessidade de viver junto com os outros nasce as tendências de preservações de si, de defesa e de proteção. 
A sociabilidade se constrói entre o individuo e o grupo, entre indivíduos do grupo. Nem o grupo, nem os indivíduos e nem as relações são nesse contexto estáticas.

É assim que se descreve o "amor", aqui como uma convivialidade que se apresenta em fluidez do coração, nunca estática, mas sempre em eclosões que dependem do envolvimento e da competência de cada um para realizar o ideal do grupo. Nos momentos de inspirações e de emergência os indivíduos reagem de maneira diferente e apresentam de fato variações comportamentais.

As relações interpessoais ficam facilitadas na casa por ela obedecer a um "código de santo" que convida a essa sociabilidade.

Para Schutz (1979) a sociabilidade é considerada como atos comunicativos entre um "eu" que se volta aos outros e os apreende como pessoas. Podemos então entender a sociabilidade na casa como interação social realizada no contato interpessoal direto e sincrônico no dia-a-dia dos encontros e indireto de forma assincrônica pelo sentimento de pertencer à mesma comunidade humana, mística (com referencia ao mundo dos Orixás) e simbólica através de signos exteriores como os colares. Isso, mesmo quando o membro se encontra fora da comunidade. Uma vez que os laços de parentesco de santo são criados na iniciação, se mantêm pelo resto da vida. Isto não é de forma automática, mas pela atualização desses laços na ligação à casa de origem. Desse modo, o pai tem uma filha de santo no Rio de Janeiro que forma parte da comunidade, mesmo que esteja longe. O contato dela se faz por ligações telefônicas.

As cerimônias favorecem também a criação de um ambiente de sociabilidade em um nível mais superficial, no simples fato de estar junto, de se sentir membro de uma mesma família e em um nível mais profundo, na criação de amizade entre pessoas que sentem maior sintonia.

Nota-se na tradição sociológica ou nas ciências sociais um interesse pela abordagem relacional nos estudos sobre individualidade. Autores como Marx, Simmel, Weber, Trade, etc trabalharam essa temática. $\mathrm{Na}$ minha tentativa de estudar a construção de individualidade no Ilê do paizinho, procurei dialogar com as diferentes formas de abordagens da singularidade individual nas novas sociologias contemporâneas. Reflexões filosóficas e conceitualizações sociológicas se complementam então em análises que explicam como a individualidade tem a ver com a identidade pessoal e nesse caso implica certa duração no tempo da pessoa, mas engloba também considerações que vão além da identidade pessoal, quer dizer, o que existe na 
pontualidade de um momento fugaz. A respeito da relação entre individualidade e identidade da pessoa, Paul Ricoeur (1990) nota "mêmeté" e "ipséité" duas noções que se complementam e permanecem na pessoa. A mêmeté segundo ele é o que faz a continuidade na pessoa, equivalente ao habitus na sociologia de Bourdieu (1980), ele define o caráter da pessoa. São disposições duráveis que identificam uma pessoa. Bourdieu o define como "sistema de disposições duráveis e transposáveis incorporados pelo indivíduo mediante a educação". Ele distingue habitus de classe e habitus individuais. A identidade "ipséité" se apresenta sempre para Ricoeur como a parte subjetiva da identidade pessoal e orienta a procura de uma autenticidade pessoal. Uma continuidade no ser si mesmo, para si (Ricoeur, 1990:148). Trata-se de uma subjetividade que estrutura-se através da sociabilidade da pessoa. Dubet apresenta-a como a emergência e consolidação de um eu que impede o individuo de exercer plenamente o papel que desempenha ou a posição que ele ocupa possibilitando dar coerência a uma experiência por natureza dispersada (Dubet, 1994:129). Um terceiro momento na construção dessa individualidade seria os qualificados momentos de subjetivação. Luc Boltanski (1990) trabalhou na sociologia dos estados de ágape esses momentos de subjetivações como terceira identidade qualificadora do indivíduo. (Boltanski cit. por Corcuff, 2005).

Um dos métodos de apreensão da individualidade na sociologia contemporânea é a abordagem de habitus. Habitus significa a presença determinante do passado incorporado ao presente. O conceito de habitus entendido como sistema de disposições duráveis e transponíveis, adquirido por uma pessoa, pressupõe certa heterogeneidade da pluralidade de disposições no mesmo indivíduo. A sociologia de bricolagem de Bastide no campo religioso afro participa também dessa mesma lógica do pluralismo do indivíduo. Bastide trata dessa sociologia de bricolagem como um arranjo. A casa de religião onde eu pesquisei apresenta uma mistura racial de brasileiros e de afro brasileiros, mas não seria necessário abordar a questão a partir do ângulo racial para análise da pluralidade de habitus dos membros. Eles pertencem a diferentes camadas sociais e isso é um fato bastante revelador das dissonâncias, cujas origens provem das diferenciações da sociedade brasileira contemporânea portadora de várias instituições de socialização. Lahire nesse contexto afirma: “A pluri-socialização dos indivíduos nas sociedades diferenciadas é o que da conta da variação inter-individual dos comportamentos deles" (Lahire, 2004: 737). O sentido subjetivo de "si mesmo" que 
Bourdieu (1986) considera como "ilusão biográfica" se opõe segundo ele ao habitus. Portanto, esse sentido subjetivo de "si mesmo" não se limita a uma auto-análise de si, mas, etnograficamente falando, é uma parte ativa da experiência cotidiana do sujeito que se observa "nos momentos de subjetivações" que não são momentos de inspirações reflexivas de um habitus, mas momentos de "surgimentos subjetivos na situação". Eles possibilitam visualizar certa fluidez nos momentos da ação e de interação.

No processo de construção da individualidade em antropologia, optamos por uma visão fluida da pessoa. O amor, a convivialidade no campo específico estudado se apresenta como uma dinâmica de interação. É signo de humanidade, de emergência na espontaneidade em contra ponto a uma "individualidade fechada". "Humanidade" aqui não se opõe a "animalidade", mas a certa individualidade "fechada". Além disso, as crises parecem aqui se revelar como momentos de subjetivações que possibilitam essa fluidez, essa emergência do sujeito na ação.

\section{Conclusão}

O Batuque se apresenta aqui como um sistema de representações e de ações individuais e coletivas influenciadas pelas estruturas sociais, mas em mudanças perpetuas a partir das formas de apropriações de si, da emergência do sujeito. Essas mudanças operam nos momentos em que o sujeito surge na ação.

A partir dessa antropologia de emergência do sujeito analisamos a fluidez de coração nos comportamentos dos membros da casa de religião cujas ações não são totalmente condicionadas pelos habitus, nem tampouco pela identidade "ipseité" do sujeito subjetivo, mas elas são também inspiradas nos momentos de surgimentos. Assim temos um indivíduo corpo pensante fluido e totalizante. É ele que tem uma grande flexibilidade de ação e de interação.

Fazendo um breve retorno às relações entre a Igreja Católica e as religiões tradicionais em Benin, que estimularam essa pesquisa sobre a fluidez do coração, sociabilidade e individualidade no Batuque Rio-grandense, podemos afirmar que se Deus é Amor, ele não é católico, mas "Humano", deslocando de certo modo as fronteiras institucionais entre as religiões. Ao menos antropologicamente pensando, o amor não diz respeito à exclusividade de uma religião, nem mesmo de um indivíduo. Apresenta-se como um fluxo constante entre individualidade e sociabilidade. 
Referências

BASTIDE, Roger. "Mémoire collective et sociologie du bricolage". In : L'année sociologique. Paris: PUF, 1971. p. 65-108.

BENOIST, Jocelyn. "La subjectivité". In: Notions de philosophie II, Sous la direction de Denis Kambouchner, collection Folio. Paris: Gallimard, 1995.

BOLTANSKI, Luc. L'Amour et la Justice comme compétences - Trois essais de sociologie de l'action. Paris : Métailié, 1990.

BOURDIEU, Pierre (sous la direction de), La misère du monde. Paris: Seuil, 1993.

BOURDIEU, Pierre. La distinction - Critique sociale du jugement. Paris: Minuit, 1979. . Le sens pratique. Paris: Minuit, 1980.

Sociales, n. 62-63, juin 1986.

"L’illusion biographique". In : Actes de la Recherche en Sciences

CORCUFF, Philippe. "Figures de l'individualité, de Marx aux sociologies contemporaines". In : Espaces Temps.net. Textuel 12.07.2005. Disponível em : http://espacestemps.net/document1390.html.

DUBET, François. La sociologie de l'expérience. Paris: Seuil, 1994.

ECKERT, Cornelia e ROCHA, Ana Luiza Carvalho da. "Imagens do tempo: por uma etnografia da duração". In: O tempo e a cidade. Porto Alegre: Ed. UFRGS, 2005. p.139154.

LAHIRE, Bernard. Portraits sociologiques - Dispositions et variations individuelles, , coll. Essais \& Recherches. Paris: Nathan, 2002.

La culture des individus - Dissonances culturelles et distinction de

soi. Paris: La Découverte, 2004.

RICOEUR, Paul. Soi-même comme un autre, coll. Points. Paris: Seuil, 1990.

SCHUTZ, Alfred. "O mundo das relações sociais". In: WAGNER, Helmut R. (Org.). Fenomenologia e relações sociais: textos escolhidos de Alfred Schutz. Rio de Janeiro: Jorge Zahar, 1979. p. 123-193.

SILVA, Carlos Alberto F. da; SILVA, Michèle Tancman Candido da. A dimensão socioespacial do ciberespaço: uma nota. Rio de Janeiro: Fundação CECIERJ, 2007. Disponível em: http://www.educacaopublica.rj.gov.br/biblioteca/geografia/geo07b.htm

SIMMEL, Georg. "Sociabilidade: um exemplo de sociologia pura ou formal". In: MORAES FILHO, Evaristo. (Org.). Sociologia. São Paulo: Ática, 1996. p. 165-181.

MAGGIE, Yvonne. Guerra de Orixá: um estudo de ritual e conflito. Rio de Janeiro: Jorge Zahar, 1979.

Recebido em: 22/12/2010

Aprovado em: 28/04/2011

Iluminuras, Porto Alegre, v.12, n. 28, p. 209-221, jul./dez. 2011 